\title{
Neurophysiological Evidence for Underspecified Lexical Representations: Asymmetries With Word Initial Variations
}

\author{
Claudia K. Friedrich, Aditi Lahiri, and Carsten Eulitz \\ University of Konstanz
}

\begin{abstract}
How does the mental lexicon cope with phonetic variants in recognition of spoken words? Using a lexical decision task with and without fragment priming, the authors compared the processing of German words and pseudowords that differed only in the place of articulation of the initial consonant (place). Across both experiments, event-related brain potentials indicated that pseudowords with initial noncoronal place (e.g., *Brachen) activate words with initial coronal place (e.g., Drachen [dragon]). In contrast, coronal pseudowords (e.g., *Drenze) do not as effectively activate noncoronal words (e.g., Grenze [border]). Thus, certain word onset variations do not hamper the speech recognition system. The authors interpret this asymmetry as a consequence of underspecified coronal place of articulation in the mental lexicon.
\end{abstract}

Keywords: speech recognition, lexical activation, underspecification, ERPs, fragment priming

No sound is ever acoustically identical, even when spoken in the same context by the same speaker. One type of ambiguity in the signal comes from systematic changes such as assimilation. For example, in German and English, consonants that are typically produced with a coronal place of articulation ( place; e.g., /t, d, n/) appear to borrow the place of the segment that immediately follows. The $/ \mathrm{n} /$ in rain, for example, can adopt the place of the following labial $/ \mathrm{b} /$ in rainbow. Consequently, rainbow can be pronounced as *raimbow. Several studies demonstrated that spoken language processing successfully deals with such variations (Coenen, Zwitserlood, \& Bölte, 2001; Gaskell \& Marslen-Wilson, 1996, 1998; Gow, 2001, 2002, 2003; Gumnior, Zwitserlood, \& Bölte, 2005; Lahiri \& Marslen-Wilson, 1991, 1992; Mitterer \& Blomert, 2003; Mitterer, Csépe, Honbolygo, \& Blomert, 2006; Weber, 2001, 2003). However, certain positions in a word are more vulnerable to variation than others. Place assimilation often appears in word final positions, but is most unusual for word initial sounds. In the present article, we investigate onset variation for words and pseudowords spoken in isolation to learn more about the nature of lexical representation and activation.

Claudia K. Friedrich, Aditi Lahiri, and Carsten Eulitz, Department of Linguistics, University of Konstanz, Konstanz, Germany.

Aditi Lahiri is now at the Faculty of Linguistics, Philology, and Phonetics, University of Oxford, Oxford, England.

In addition to the departmental support at the University of Konstanz, this work was supported by the German Research Foundation through the Leibniz Prize, awarded to Aditi Lahiri; the SFB 471 project, led by Aditi Lahiri and Carsten Eulitz; and a grant to Claudia K. Friedrich (FR 2591/ 1-1). We also received assistance directly from the Ministry of Science, Research, and the Arts of Baden-Württemberg, Germany, in the form of a grant to Aditi Lahiri. For her help in data acquisition, we are enormously grateful to Barbara Awiszus.

Correspondence concerning this article should be addressed to Claudia K. Friedrich, who is now at the Department of Biological Psychology and Neuropsychology, University of Hamburg, Von-Melle-Park 11, 20146 Hamburg, Germany. E-mail: Claudia.Friedrich@uni-hamburg.de
Different explanations have been proposed to explain how variation is handled by the listeners to correctly identify word forms. Some approaches strengthen the importance of context for the correct recognition of assimilated forms. Gaskell and MarslenWilson $(1996,1998)$ argued that mapping speech onto lexical representations involves online phonological inference that detects systematic variations. In both cross-modal priming and phoneme monitoring they showed that perceptual compensation for assimilation only occurs when following context makes assimilation phonologically legal. These authors concluded that listeners cope with assimilation by inverting phonological rules in a given context. Presented with raimbow, listeners are assumed to infer that a labial followed by another labial may be an underlying coronal. A further cross-modal priming study by Gaskell and Marslen-Wilson (2001) revealed that if assimilation creates lexical ambiguity (e.g., run/rum), contextual compensation only occurs if the sentence meaning favors the assimilated form.

A combined impact of context and phonetic detail is proposed by other authors. To account for a series of phoneme monitoring and form priming experiments, Gow $(2001,2002,2003)$ has argued that assimilation does not change a feature completely but provides information about both the underlying form of the assimilated segment and the surface form of the following segment. According to this point of view, listeners detect assimilated features, use this information to anticipate the upcoming segment, and align the assimilated feature to this subsequent element. Similarly, Mitterer and colleagues (Mitterer \& Blomert, 2003; Mitterer et al., 2006) argue that context in combination with phonetic detail drives compensation for assimilation. Using word identification experiments and mismatch detection as reflected in event-related brain potentials (ERPs), they showed that unviable variation of coronal elements is less often confused with canonical word forms than viable variation of those elements and that this only holds if phonetic detail signals assimilation.

Next to empirical evidence supporting contextual influences on the recognition of assimilated forms, some recent results in English and in German suggest that listeners are equally tolerant of con- 
textually appropriate and inappropriate changes of coronal elements (Gumnior et al., 2005; Wheeldon \& Waksler, 2004). Such undisrupted access for assimilated forms even if they appear in illegal contexts or in isolation can be captured by the assumption of a featurally underspecified lexicon (FUL; Lahiri \& MarslenWilson, 1991, 1992; Lahiri \& Reetz, 2002). According to the FUL model, the coronal place is not represented in the mental lexicon of the listener; one of the reasons is that coronals frequently undergo surface variation. FUL explains the finding that assimilated forms activate the underlying words regardless of the following element by assuming that no place feature for coronal elements is represented in the stored lexical representation. Accordingly, the changed place feature of *raim does not mismatch the empty place slot of rain.

The assumption of underspecified representations in FUL contrasts to fully specified entries that are assumed in the majority of contemporary connectionist models of spoken word recognition since the TRACE model (McClelland \& Elman, 1986). In FUL, only place representations that do not assimilate are fully specified. For example, words ending with a labial element like $/ \mathrm{m} /$ in plum or a dorsal element like /g/ in flag will never become plun or flad. The mapping of the acoustic signal to specified and underspecified entries leads to asymmetric activation patterns following a ternary matching logic, which depends on the extracted features and on the presence or absence of those features in the representations of a word (Fitzpatrick \& Wheeldon, 2000; Lahiri \& Reetz, 2002;). A match refers to situations in which signal and representation contain the same information. A no-mismatch occurs if an extracted feature is not represented in the lexicon. This means that elements with labial or dorsal place that are present in the signal do not mismatch with empty place slots of coronals. In contrast, a mismatch is detected if signal and representation contain incompatible features. Elements with coronal place mismatch with representations that have a labial or dorsal place specified. According to FUL, listeners reject mismatching lexical candidates, whereas matching or no-mismatching words remain activated.

Electrophysiological measures have proven to be a fruitful approach to investigate feature extraction in speech perception and feature mapping to the mental lexicon. It has been shown using the $\mathrm{N} 100 \mathrm{~m}$ component that the speech recognition system has the place of vowels and stop consonants available around $100 \mathrm{~ms}$ after stimulus onset (Obleser, Eulitz, \& Lahiri, 2004; Obleser, Scott, \& Eulitz, 2006). The representation of those features in the mental lexicon has been studied by means of a component that occurs at around $200 \mathrm{~ms}$ after stimulus onset, the mismatch negativity (MMN; see Näätänen, 2001, for an overview). Eulitz and Lahiri (2004) provided the first neurobiological evidence for the ternary matching logic assumed by FUL. They presented three vowels used as standards and deviants in all possible combinations. Mental representations of the vowels were either fully specified in the lexicon (e.g., /o/ with a dorsal place, which is represented in the mental lexicon) or underspecified (e.g., / $/ /$ and $/ \mathrm{e} /$, for which [coronal] is not specified in the mental lexicon). Latency and amplitude of the MMN was found to reflect the degree of conflict between place features activated by the standards and those extracted from the deviants. The pattern of MMN differences supported the notion of underspecification of the feature coronal in the mental lexicon.
The present experiments test the neurophysiological validity of the FUL model by means of words and meaningless letter strings (pseudowords) that only differ in their initial place. The initial element either had a coronal place $(/ \mathrm{d} /, / \mathrm{t} /, / \mathrm{n} /)$ or had a noncoronal place that could be either labial $(/ \mathrm{b} /, / \mathrm{p} /, / \mathrm{m} /)$ or dorsal $(/ \mathrm{g} /, / \mathrm{k} /$; note that $/ \mathrm{y} /$ is not a legal onset element of German words and was therefore not realized). Consider the German words Grenze [border], with a noncoronal place of the initial element, or Drachen [dragon], with a coronal place at the beginning. According to FUL, the dorsal place of Grenze is stored in the listeners' mental lexicon. Hence, a pseudoword that differs in place like $*$ Drenze mismatches in this feature and should not activate the word. In contrast, there is no place specified for the lexical representation of Drachen. Therefore, the noncoronal start of a pseudoword like * Brachen does not mismatch the representation of Drachen and should activate this word (see Table 1 for further illustration of the ternary matching logic proposed by FUL).

We tested FUL assumptions using ERPs recorded in a lexical decision task (Experiment 1) and in a cross-modal word fragment priming task (Experiment 2). Recently, it has been proved that ERPs allow online monitoring of access-related neuronal processes that precede behavioral responses in both tasks. Of particular interest in Experiment 1 is the onset of the N400 pseudoword effect, which immediately reflects the interruption of normal word processing (Friedrich, Eulitz, \& Lahiri, 2006; O'Rourke \& Holcomb, 2002). In Experiment 2, we focus on the P350 effect, which has been related to the lexical activation that the target words receive from the preceding prime fragments (Friedrich, 2005; Friedrich, Kotz, Friederici, \& Alter, 2004; Friedrich, Kotz, Friederici, \& Gunter, 2004). Both ERP effects are highlighted in more detail in the introduction to each experiment.

\section{Experiment 1}

The findings of a number of studies suggest that a specific ERP component, the N400, might be sensitive to the time-course of cognitive processes underlying word comprehension. The N400 is a negative-going component with peak latency around $400 \mathrm{~ms}$. After its first description by Kutas and Hillyard (1980), the N400 has not only been related to aspects of semantic processing in sentence and priming contexts (see Kutas \& Federmeier, 2000, for

Table 1

Predictions of the FUL Model as Tested in Experiments 1 and 2

\begin{tabular}{cccc}
\hline & $\begin{array}{c}\text { Extracted } \\
\text { place }\end{array}$ & $\begin{array}{c}\text { Stored } \\
\text { place }\end{array}$ & Matching \\
\hline Acoustic signal & \multicolumn{4}{c}{} \\
\hline Activation of words with noncoronal initial & $\begin{array}{c}\text { element } \\
\text { (e.g., }\end{array}$ & Grenze) \\
Grenze & dorsal & dorsal & match \\
Drenze (nonword) & coronal & dorsal & mismatch \\
Activation of words with coronal initial & element (e.g., & Drachen) \\
Drachen & coronal & empty & no-mismatch \\
Brachen (nonword) & dorsal & empty & no-mismatch \\
\hline
\end{tabular}

Note. Lexical entries of words with initial noncoronal elements have a specified slot for place of articulation (place). Place information extracted from the signal either matches or mismatches the stored place. In contrast, lexical entries of words with initial coronal elements have an empty slot for place, and hence, no place information extracted from the signal does mismatch. FUL $=$ featurally underspecified lexicon. 
a review), but also to the recognition of isolated words. Of particular relevance to Experiment 1 are studies that compared the N400 effect for words and word-like spoken or written strings (pseudowords). In virtually all of these studies the N400, peaking at $400 \mathrm{~ms}$ for written words and between 400 and $600 \mathrm{~ms}$ for spoken words, has been remarkably larger and has lasted longer for pseudowords than for words (e.g., Attias \& Pratt, 1992; Bentin, 1987; Holcomb, Grainger, \& O'Rourke, 2002; Picton \& Hillyard, 1988; Soares, Collet, \& Duclaux, 1991). The pseudoword N400 effect is discussed to reflect enhanced lexicosemantic memory search for pseudowords that have no lexical representation (e.g. Supp et al., 2004).

It appears as if the N400 pseudoword effect diverges as a function of the amount of information provided by the temporally unfolding speech signal. Words and pseudowords do not differ for the initial N400 component, presumably because the speech signal activates several alternatives in the listeners' mental lexicon. Thereafter, enhanced N400 amplitude for pseudowords seems to reflect more processes than enhanced lexical search. O'Rourke and Holcomb (2002) adjusted ERPs to recognition points of spoken words and deviation points of spoken pseudowords. They observed that words with early versus late recognition points did not differ in the N400 component, whereas pseudowords with late deviation points produced earlier N400 peaks in the time-locked analysis compared to pseudowords with early deviation points. They concluded that the N400 time course for words initially reflects normal fast word processing, whereas the pseudoword data suggest that these measures are also sensitive to later top-down processes

Recently we tested coronal and noncoronal pseudowords that diverged from words in word medial place. Both types of pseudowords elicited enhanced N400 amplitude, but by adjusting ERPs to the words' uniqueness points and the pseudowords' deviation points, we were able to show an asymmetric onset pattern. We observed that the N400 pseudoword effect starts 150 $\mathrm{ms}$ earlier for coronal pseudoword variants (e.g., *Horbe diverging from Horde [horde]) than for noncoronal variants (e.g., *Prode diverging from Probe [test]). That is, noncoronal pseudowords were handled longer as words by the recognition system than coronal pseudowords (Friedrich et al., 2006). This is exactly what one would predict on the basis of the FUL model. Here the lexical representation of Probe has a [labial] place specified for medial /b/. *Prode, which mismatches this specified place, cannot activate Probe and therefore elicits an earlier N400 pseudoword effect. In contrast, the coronal place of / $\mathrm{d} /$ in Horde is not represented in the lexicon. *Horbe, which does not mismatch this empty place slot, activates Horde and therefore does not elicit an early N400 pseudoword effect.

Experiment 1 tests the asymmetric onset of the N400 pseudoword effect for coronal and noncoronal words and pseudoword variants that differ in initial POA. As sketched above, FUL assumes that coronal pseudoword variants, which mismatch a word in the dorsal place feature of the initial element, should not activate the original word (e.g., *Drenze derived from Grenze). In contrast, there is no initial place specified for coronal words, and thus noncoronal pseudoword variants (e.g, *Brachen derived from Drachen) should activate the original word. Taking our assumptions together, lexical processing of coronal pseudowords should be interrupted earlier than processing of noncoronal pseudowords. This should be reflected in an earlier onset of the N400 pseudoword effect for coronal pseudowords than for noncoronal pseudowords.

\section{Method}

Participants. The participants were 16 undergraduate students from the University of Konstanz community (8 men and 8 women). All participants were native speakers of German with no discernible uncorrected deficits in hearing or vision. The participants in this and in the following experiment were paid for their participation or received course credit points. No participant took part in both experiments reported.

Stimuli. One hundred and twenty familiar German disyllabic nouns beginning with a stop or a nasal with stress on the first syllable were selected (see Appendix). Half of the words began with a coronal consonant and the other half with a noncoronal consonant. A pseudoword with the opposite place feature was formed for each word. To ensure that the first syllables of the pseudowords could not be the first syllables of existing German words, we checked them using an online German dictionary (http://wortschatz.uni-leipzig.de). When syllable structure, number of syllables, and stress were taken into account, no German word shared the first syllables with the pseudowords. Frequency of coronal and noncoronal words was matched using the online dictionary. That is, each coronal word had a noncoronal counterpart with exactly the same frequency.

All words and pseudowords were spoken by a female native speaker of German in a sound attenuating chamber. The speaker was naïve with respect to the experimental manipulation and the hypotheses of the study. She read the stimuli in a fluent style from lists in which a word was immediately followed by the respective pseudoword. The speaker was instructed to pronounce the pseudowords in the same way as the words. Stimuli were recorded on a digital audiotape recorder at a sampling rate of $44.1 \mathrm{kHz}$ using a high-quality microphone. The recordings were then transferred to computer, volume equalized, and edited into individual tokens using the Cool Edit 2000 (Syntrillium Software; Phoenix, AZ) waveform manipulation software package. If possible, single periods were deleted from either the word or the pseudoword to equalize the duration of the stimuli. This resulted in the same mean lengths of coronal words and noncoronal pseudowords $(M=871$ $\mathrm{ms}, S D=131$ for both), and the same mean lengths for noncoronal words and coronal pseudowords $(M=957 \mathrm{~ms}, S D=109$ for both).

Uniqueness points of the words and deviation points of the pseudowords were established using the CELEX database (Baayen, Piepenbruck, \& Van Rijn, 1993). Scanning from left to right, we determined the first phoneme of the words that made them unique with respect to any monomorphemic, disyllabic, first-syllable stressed word in the database and also the first phoneme of the pseudowords that made them distinguishable from this group of words. Next, the onset of the deviating phonemes (which was the onset of the closure period for plosives, the onset of the first period for nasals, the onset of the transition for laterals, and the onset of the noise in affricates and fricatives) was determined in the acoustic signal using waveforms and spectrograms. Uniqueness points were $44 \mathrm{~ms}$ later for words than deviation points for pseudowords, $F(1,59)=12.20, p<.001$, and uniqueness/deviation points were $44 \mathrm{~ms}$ later for noncoronal words and 
coronal pseudowords than for coronal words and noncoronal pseudowords, $F(1,59)=8.97, p<.01$. Both factors did not interact, $F(1,59)=0.08$. Mean uniqueness points were $350 \mathrm{~ms}$ $(S D=109)$ for coronal words and $398 \mathrm{~ms}(S D=115)$ for noncoronal words. Mean deviation points were $351 \mathrm{~ms}(S D=109)$ for coronal pseudoword variants and $310 \mathrm{~ms}(S D=113)$ for noncoronal pseudoword variants. Uniqueness and deviation point measures were used to adjust the ERP and behavioral data.

Procedure. Sintered silver-silver chloride electrodes were held in place on the scalp with an elastic cap (EASY Cap; EASYCAP Gmbh, Herrsching, Germany). Scalp locations included 62 standard international 10-20 system locations. Two additional electrodes to control for eye movements were placed below the eyes. All electrodes were online referenced to $\mathrm{Cz}$. Original average reference was used for the analysis of ERPs. All electrode impedances were less than $5 \mathrm{k} \Omega$. The electroencephalogram was recorded with a sampling rate of $250 \mathrm{~Hz}$.

Participants sat in a sound attenuated booth and made speeded lexical decisions to stimuli presented at a comfortable listening level (Sony loudspeakers). A trial started with a fixation point presented in the center of a computer screen. $200 \mathrm{~ms}$ after the onset of the fixation point, a spoken stimulus was presented. The fixation point remained throughout the spoken stimulus and was terminated with the participant's response. Participants were told not to blink and to look at the fixation point as long it appeared on the screen. Following the fixation point there was a $1.5 \mathrm{~s}$ blank screen intertrial interval. Participants were told they could blink during this interval. Half the participants made "yes" responses with the thumb of their left hand and "no" responses with the thumb of their right hand; for the remaining participants, response hands were reversed. Speed and accuracy were stressed equally. Participants were given a break after completing half of the trials.

Data analysis. Error rates were calculated for all stimuli. Reaction times and ERPs were calculated only for correctly responded trials. Eye blinks and movements were systematically recorded from each participant before the experimental task started. Characteristic scalp topographies of eye artifacts were corrected from the experimental data using Brain Electrical Source Analysis (BESA; MEGIS Software GmbH, Gräfelfing, Germany). We applied the same ERP analysis as in our previous study (Friedrich et al., 2006) to the present data. The ERP data were quantified by calculating the mean amplitudes (relative to a $200 \mathrm{~ms}$ prestimulus baseline). From stimulus onset we analyzed a time window from 500 to $1000 \mathrm{~ms}$ to approve the pseudoword N400 effect. ERPs adjusted to uniqueness and deviation points were analyzed in two latency windows (early N400: 100-250 ms; late N400 and late positivity: $700-750 \mathrm{~ms}$ ).

We used the SAS statistical analysis system for statistical analyses. Two factors entered the analyses of variance (ANOVAs) for behavioral data: lexical status (words vs. pseudowords) and coronality (coronal words, and noncoronal pseudowords vs. noncoronal words and coronal pseudowords). As in our previous study, there were no asymmetries visible in the topographics of the ERP effects. Thus, we applied the same regions of interest (ROIs) as in the former study, both including 20 lateral and midline electrode positions. An anterior ROI comprised electrodes $\mathrm{AF} 7, \mathrm{AF} 3, \mathrm{AFz}$, AF4, AF8, F5, F1, Fz, F2, F6, FC3, FC1, FCz, FC2, FC4, C5, C3, $\mathrm{Cz}, \mathrm{C} 4$, and C6; a posterior ROI comprised electrodes CP5, CP3, CP1, CPz, CP2, CP4, CP6, P7, P3, P1, Pz, P2, P4, P8, T7, TP7, $\mathrm{TP} 8, \mathrm{~T} 8, \mathrm{PO} 1$, and $\mathrm{PO} 2$. A factor region (anterior vs. posterior) was added to the ANOVA described for the behavioral data accordingly. We report partial eta-squared $\left(\eta_{p}^{2}\right)$ as an estimator of the proportion of variance accounted for by a given effect.

\section{Results}

Behavioral results. Mean reaction times from stimulus onset and from uniqueness or deviation points as well as error rates are shown in Table 2. Starting from stimulus onset, participants needed $1,184 \mathrm{~ms}$ to correctly identify a word, and 1,256 ms to correctly reject pseudoword variants. Accordingly, the ANOVA for reaction times from stimulus onset revealed a main effect of lexical status, $F_{1}(1,15)=89.76, p<.001, \eta_{p}^{2}=.75 ; F_{2}(1,59)=$ 21.86, $p<.01, \eta_{p}^{2}=.21$. Furthermore, responses were faster for coronal words and their noncoronal variants than for noncoronal words and their coronal variants, $F_{1}(1,15)=17.49, p<.01 ; F_{2}(1$, $59)=6.87, p=.01$. This effect might well be related to the longer duration of the former as compared to the latter stimuli. An interaction of the factors' lexical status and coronality did not reach significance, $F_{1}(1,15)=3.01, p=.10 ; F_{2}(1,59)=2.11, n s$.

A main effect of coronality was no longer observed when reaction times were adjusted to uniqueness and deviation points, $F_{1}(1,15)$ and $F_{2}(1,59)<1$. Participants needed $791 \mathrm{~ms}$ to correctly identify the words after their uniqueness points, and 902 $\mathrm{ms}$ to correctly reject pseudowords after their deviation points. Significance of this effect was approved by a main effect of lexical status, $F_{1}(1,15)=182.68, p<.001, \eta_{p}^{2}=.92 ; F_{2}(1,59)=38.94$, $p<.01, \eta_{p}^{2}=.40$. Again, there was no significant interaction of the

Table 2

Mean Reaction Times (RT) and Error Rates (With Standard Deviations) for All Conditions in Experiment 1

\begin{tabular}{|c|c|c|c|c|c|c|}
\hline \multirow[b]{2}{*}{ Variable } & \multicolumn{2}{|c|}{$\begin{array}{l}\text { RT from word } \\
\text { onset (ms) }\end{array}$} & \multicolumn{2}{|c|}{$\begin{array}{c}\text { RT from } \\
\text { uniqueness/deviation } \\
\text { points (ms) }\end{array}$} & \multicolumn{2}{|c|}{ Error rate $(\%)$} \\
\hline & $M$ & $S D$ & $M$ & $S D$ & $M$ & $S D$ \\
\hline Noncoronal words & 1212 & 147 & 796 & 122 & 2.7 & 1.4 \\
\hline Coronal pseudowords & 1271 & 121 & 895 & 105 & 0.9 & 0.8 \\
\hline Coronal words & 1156 & 145 & 786 & 118 & 2.3 & 1.5 \\
\hline Noncoronal pseudowords & 1242 & 148 & 908 & 118 & 1.6 & 0.9 \\
\hline
\end{tabular}


factors lexical status and coronality, $F_{1}(1,15)=2.03, n s ; F_{2}(1$, $59)<1$.

Overall error rates were low (less than 3 percent, which is one to two errors per condition per subject; compare Table 2). ANOVA for error rates revealed a main effect of lexical status, $F_{1}(1,15)=$ $13.71, p<.01, \eta_{p}^{2}=.49 ; F_{2}(1,59)=7.77, p<.01, \eta_{p}^{2}=.62$. Participants made fewer hits than correct rejections. That is, they made more errors for words than for pseudowords, indicating a weak response bias toward "no" responses. An interaction of factors lexical status and coronality only reached significance for the by-participant analysis, $F_{1}(1,15)=5.02, p=.04, \eta_{p}^{2}=.25$, but not for the by-item analysis, $F_{2}(1,59)=2.28, p=.13$. In sum, participants recognized both types of mispronunciation and rejected the pseudowords accordingly.

ERPs time-locked to stimulus onset. The ERP grand mean waveforms time-locked to the onsets of the words and pseudoword variants for selected anterior and posterior electrode sites are plotted in Figure 1A. For all the ERPs, the first visible component was a negative-going deflection peaking at $130 \mathrm{~ms}$ after stimulus onset (N1). This was followed by a positive deflection occurring at approximately $200 \mathrm{~ms}$ (P2). Starting at $300 \mathrm{~ms}$ a broad negativity was observed, which was enhanced for pseudoword variants as compared to words and is henceforth referred to as the N400 pseudoword effect. At some posterior electrode sites, the N400 was followed by a late positivity ranging between 600 and 1500 ms.

A time window ranging from 500 to $1000 \mathrm{~ms}$ was analyzed to establish the N400 pseudoword effect time-locked to stimulus onset. A significant effect of lexical status was observed in this time window, $F(1,15)=43.37, p<.001, \eta_{p}^{2}=.74$. ERPs were more negative for pseudowords than for words. Furthermore, an interaction of region, lexical status and coronality reached signif-

\section{ERPs Time-locked to Word Onset}
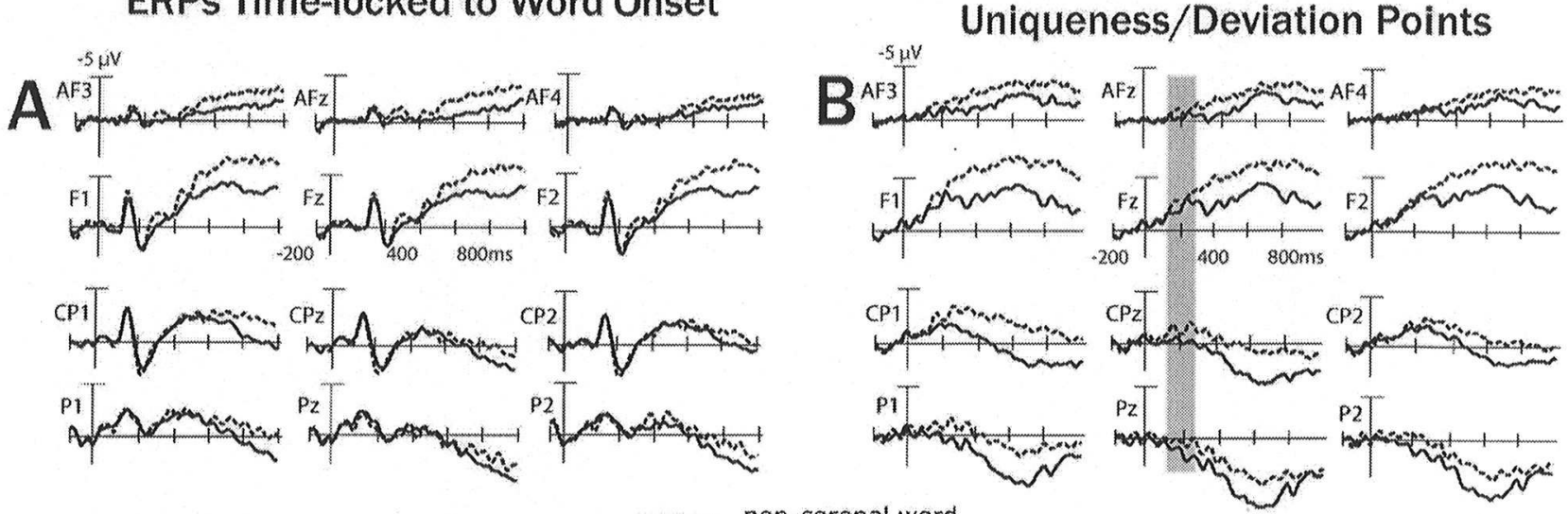

non-coronal word

coronal variant
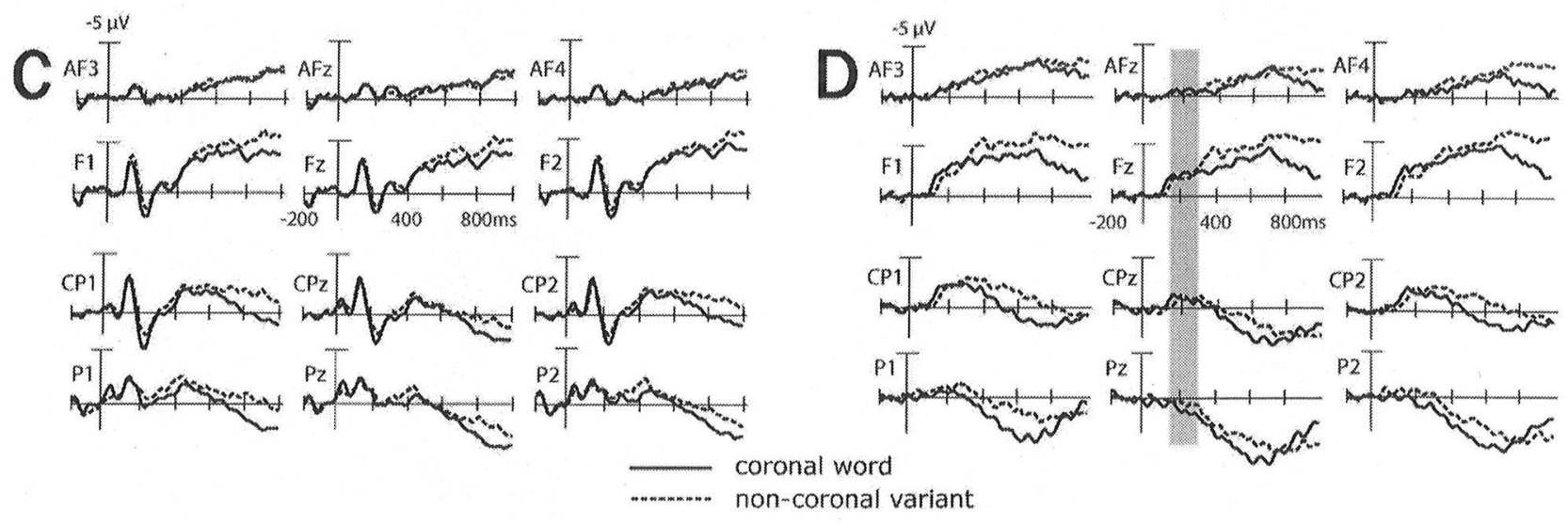

coronal word
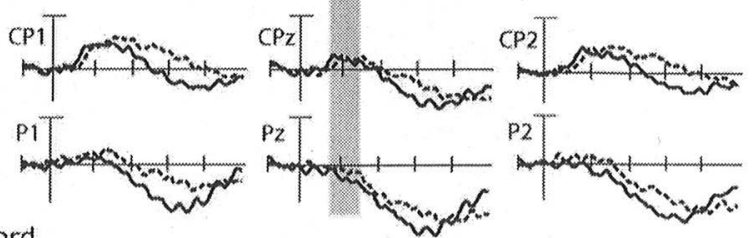

non-coronal variant

Figure 1. Plotted in this figure are the grand average event-related brain potentials (ERPs) for words and pseudowords for selected electrode sites in Experiment 1. ERPs adjusted to stimulus onset are shown on the left side. ERPs adjusted to uniqueness and deviation points are shown on the right side. Black solid lines are ERPs from words and black dashed lines are ERPs from pseudowords. ERPs for noncoronal words and coronal pseudowords are illustrated in Panels A and B; ERPs for coronal words and noncoronal pseudowords are illustrated in Panels C and D. The initial part of the N400 pseudoword effect, which starts earlier for coronal than for noncoronal pseudowords, is highlighted in grey. 
icance, $F(1,15)=7.57, p=.01, \eta_{p}^{2}=.34$. A significant interaction of lexical status and coronality was only found for anterior electrode leads, $F(1,15)=5.11, p<.05, \eta_{p}^{2}=.25$. Post hoc comparisons revealed that both types of pseudowords elicited enhanced anterior pseudoword negativity as compared to their respective words, coronal pseudowords: $F(1,15)=25.01, p<$ $.001, \eta_{p}^{2}=.40$; noncoronal pseudowords, $F(1,15)=16.13, p<$ $.01, \eta_{p}^{2}=.52$. However, the interaction indicated that the difference between coronal pseudoword variants and their respective words was stronger - that is, the pseudoword N400 was greaterthan the differences between noncoronal pseudoword variants and their respective words.

Overall, an N400 pseudoword effect was established in Experiment 1 , and it appeared as if this effect was enhanced for coronal pseudowords. However, temporal analysis of the pseudoword N400 effect has to consider different uniqueness and deviation points within and across conditions. Next we adjusted the ERPs to the point in time where the differences between the words and their respective pseudowords occurred in the acoustic signal.

ERPs time-locked to uniqueness and deviation points. The averaged ERP signals time-locked to the uniqueness and deviation points of the words and pseudoword variants for selected anterior and posterior electrode leads are shown in Figure 1B. The ERPs zoom into the N400 effect and the late positivity. In parallel to our previous study (Friedrich et al., 2006), we analyzed a time window ranging from 100 to $250 \mathrm{~ms}$ after uniqueness and deviation points to investigate the beginning of the $\mathrm{N} 400$ pseudoword effect. The later N400 was analyzed in a time window ranging from 250 to $750 \mathrm{~ms}$.

The initial part of the pseudoword N400 adjusted to uniqueness and deviation points appears to be selectively enhanced for coronal pseudowords. Indeed, the corresponding three-way ANOVA revealed an interaction of lexical status and coronality $F(1,15)=$ $7.84, p=.001, \eta_{p}^{2}=.36$. Coronal pseudowords derived from their base words in this early N400 effect, $t(15)=8.41, p=.01, \eta_{p}^{2}=$ 0.42 . In contrast, noncoronal pseudowords did not differ from their base words, $t(15)<1$. Furthermore, mean amplitudes for coronal and noncoronal words did not differ, $t(15)<1$. However, coronal pseudowords elicited larger negativity than noncoronal pseudowords, $t(15)=8.39, p=.01, \eta_{p}^{2}=.34$. Thus, the interaction appears to be completely driven by the coronal pseudowords.

The later part of the N400 pseudoword effect time-locked to uniqueness and deviation points was enhanced for both types of pseudowords as compared to words. This is reflected in a main effect of lexical status, $F(1,15)=49.49, p<.001, \eta_{p}^{2}=.74$. Coronal pseudoword variants elicited an enhanced late N400 response compared to their base words, $t(15)=39.42, p<.001$, $\eta_{p}^{2}=.71$. Similarly, noncoronal pseudoword variants elicited more negativity than their base words, $t(15)=25,83, p<.001, \eta_{p}^{2}=$ .36. In sum, an early part of the $\mathrm{N} 400$ pseudoword response reflected different processing of coronal and noncoronal variants, whereas a later part of the N400 pseudoword response was enhanced for both types of variants.

\section{Discussion}

On the basis of the FUL model, we predicted that not all pseudowords would equally disrupt word recognition in Experiment 1. More specifically, noncoronal pseudoword variants (e.g.,
*Brachen) that differ in initial POA from existing words (e.g. Drachen) should activate the corresponding word. Hence noncoronal pseudowords should be handled longer as words by the recognition system than coronal pseudoword variants (e.g., *Drenze) that do not activate the corresponding word (e.g., Grenze). In line with these assumptions and in replication of previous results (Friedrich et al., 2006), we found an asymmetric onset of the N400 pseudoword effect: Time-locked to uniqueness points of the words and deviation points of the pseudowords, the N400 effect starts $150 \mathrm{~ms}$ earlier for coronal than for noncoronal pseudowords.

The initial N400 pseudoword effect appears to reflect the asymmetric cohort activation. Up to the deviation points, processing of words and pseudowords is identical because both types of spoken strings activate a cohort of words. That is, up to the deviation points of the pseudowords, a set of word candidates is available for selection processes, and consequently N400 does not differ for words and pseudowords. Starting at the deviation points, pseudoword variants should interrupt word processing because no word of the activated cohort further fits the input. However, the cohort activated by noncoronal pseudoword variants (e.g., *Brachen) includes the original coronal word (e.g., Drachen), because the underspecified information about the POA of the respective lexical entry does not conflict with a dorsal POA. Therefore, early selection processes can access at least one possible word candidate after the deviation point, and thus the initial $\mathrm{N} 400$ for noncoronal pseudoword variants does not differ from coronal words. By contrast, the cohort activated by coronal pseudoword variants (e.g., *Drenze) does not include the original word (e.g., Grenze). Here the coronal POA extracted from the signal mismatches the [dorsal] place specified in the lexical entry. Thus, after the deviation points of noncoronal pseudoword variants no remaining candidates are available for lexical selection processes. This is reflected in the differential onset of the early N400 pseudoword effect.

Although we found neurophysiological evidence for noncoronal pseudowords activating coronal words, these variants were correctly rejected by the participants to the same degree as the coronal pseudowords. The question is, on what basis is this decision reached for noncoronal pseudowords if they can refer to the underspecified representation of the corresponding coronal words? One might account for the correct rejection by assuming phonological parsing mechanisms that are independent of initial lexical activation. A phonological matching mechanism may reject both coronal and noncoronal pseudoword variants on the basis of surface matching between the signal and the canonical form. Whether this evidence checking operation is mandatory in spoken word recognition or whether it is especially recruited to solve the lexical decision task has to be clarified in future research.

Taken together, the ERP data of Experiment 1 again suggest that the N400 for speech material is a conglomerate of multiple neurophysiological processes related to spoken word recognition (see Hagoort \& Brown, 2000; Nobre \& McCarthy, 1994). Several subprocesses of word recognition contributing to the N400 pseudoword effect have already been suggested (e.g., O'Rourke \& Holcomb, 2002; van den Brink, Brown, \& Hagoort, 2001). Our results imply that an initial part of the N400 in the lexical decision task is modulated by asymmetric activation patterns, whereas a later part reflects evidence checking at a phonemic level of analysis. These multiple processes might also explain the relatively 
long-lasting asymmetry of the N400 pseudoword effect that covered the late $\mathrm{N} 400$ window as well.

In the present study, we observed fewer accurate responses for words than for pseudowords. This result replicated our previous findings (Friedrich, Kotz, Friederici, \& Gunter, 2004) but is at odds with the generally observed pattern of more accuracy for words than pseudowords in lexical decision tasks (e.g., O'Rourke \& Holcomb, 2002). The fact that participants' decisions were biased toward "no" responses in the present experiment might have two reasons. First, there were only subtle differences between words and pseudowords (initial place of articulation in the present study, medial place of articulation in the previous one), which were not easy to detect. Second, word decision might have been more insecure because half of the pseudowords, namely noncoronal pseudowords, activated lexical entries of words.

In sum, Experiment 1 revealed neurophysiological evidence for underspecified representations of words in the mental lexicon. In Experiment 2, we tested the assumption that noncoronal pseudowords activate coronal words, whereas coronal pseudowords do not activate noncoronal words by means of word fragment priming.

\section{Experiment 2}

In word fragment priming, the onset of a spoken word (e.g., mus, originating from the spoken word music) is immediately followed by a visual word or a meaningless letter string (pseudoword). Participants are asked to decide whether they saw a word or not. Faster responses for words that match the fragment (e.g., in the fragment-word pair mus-music) as compared to unrelated words (e.g., viba-music) have been interpreted as reflecting the activation that the modality-independent representation of the word receives from the fragment (Marslen-Wilson, 1990; Spinelli, Segui \& Radeau, 2001; see Zwitserlood, 1996, for an overview). With fragment priming, it has been shown that subtle differences in the speech signal including lexical stress are used for finegrained lexical activation differences. Responses were faster when the preceding fragment had the same stress as the target, (e.g., stressed fragment mus preceding 'music) than when the fragment differed in stress (e.g., unstressed fragment mus from mus 'eum preceding 'music; Cooper, Cutler \& Wales, 2002; Cutler \& Van Donselaar, 2001; Friedrich, Kotz, Friederici, \& Alter, 2004; SotoFaraco, Sebastian-Galles, \& Cutler, 2001).

ERPs recorded in fragment priming revealed characteristic differences for matching and unrelated targets that were first described by Friedrich, Kotz, Friederici, and Gunter (2004). Difference waves resulting from the subtraction of matching words from unrelated words showed more positive amplitudes for unrelated than for matching words with a maximum peak at $350 \mathrm{~ms}$. This so-called P350 typically was characterized by a left-hemispheric topography. Comparable P350 difference waves have been shown for auditory fragments preceding visual words, as well as for visual fragments preceding visual words, leading to the conclusion that P350 differences reflect neural processing related to the identification of modality-independent lexical representations. Of special interest for the present study was the sensitivity of the P350 effect to subtle differences between the speech signal and lexical representations. Within a time range of 300 to $400 \mathrm{~ms}$, P350 differences were found to be gradually reduced when words diverged from preceding fragments in the initial nucleus (e.g., kan-Konto [account]; Friedrich, 2005), or in the stress information (e.g., ' $F a$ fdsan [pheasant]; Friedrich, Kotz, Friederici, \& Alter, 2004).

Subsequently to the P350 effect, enhanced central negativity for unrelated words as compared to matching words was reliably observed in cross-modal fragment priming. This negativity might relate to the phonological N400, which was found to be reduced for alliterating and rhyming words (Münte, Say, Clahsen, Schlitz, \& Kutas, 1999; Praamstra, Meyer, \& Levelt, 1994; Praamstra \& Stegeman, 1993; Rugg, 1987; Dumay et al., 2001; RodriguezFornells, Münte, \& Clahsen, 2002) and/or to the phonological mismatch negativity described by Connolly and Phillips (1994). It has been argued that the N400 effect does not reflect automatic lexical activation during priming (Chwilla, Brown, \& Hagoort, 1995; Chwilla, Hagoort, \& Brown, 1998; Holcomb, 1993). In line with this observation, the amplitude of the central negativity in fragment priming was found to be not sensitive to fine-grained activation differences as a function of nucleus variation (Friedrich, 2005) or pitch (Friedrich, Kotz, Friederici, \& Alter, 2004). It was argued that the $\mathrm{N} 400$ reflected strategic effects, which are assumed to assist lexical decisions in priming studies (Neely, Keefe, \& Ross, 1989; Norris, McQueen, \& Cutler, 2002; Radeau, Morais, \& Dewier, 1989). A possible mechanism that speeds up "yes" responses to matching targets might be a rough phonological matching between prime and target.

The second experiment aimed to further explore whether initial segments of noncoronal pseudoword variants, which were presented in Experiment 1, indeed activate coronal words; likewise, coronal pseudoword variants should not activate noncoronal words. Lexical activation should be reflected in amplitudes elicited in the time window of the P350 effect. Noncoronal words following coronal fragments (mismatch) should elicit amplitudes comparably to the control condition. Coronal words following noncoronal fragments (no-mismatch) should elicit amplitudes comparably to the identity condition.

\section{Method}

Participants. The participants were 16 undergraduate students from the University of Konstanz community. All participants were native speakers of German with no discernible uncorrected deficits in hearing or vision.

Stimuli. The initial syllables of each of the 120 words and 120 pseudowords used in Experiment 1 were presented as primes in Experiment 2 (see Appendix). Digitized versions from the original recordings from Experiment 1 were used. The syllables were extracted using the Cool Edit 2000 waveform manipulation software package.

The experimental design is illustrated in Table 3. Each word used in Experiment 1 was presented as a visual target in three different types of prime-target pairs: in combination with the initial syllable fragment extracted from the spoken version of that word (identity condition); in combination with the syllable fragment extracted from the corresponding pseudoword (variation condition); once in combination with an unrelated word fragment and once in combination with an unrelated pseudoword fragment (control condition). The combination of the targets with both fragment types in the control condition ensures the same number of repetitions for each fragment. Unrelated word fragments for 
Table 3

Prime-Target Pairings for Coronal and Noncoronal Words

\begin{tabular}{lll}
\hline Condition & \multicolumn{1}{c}{ Coronal word } & \multicolumn{1}{c}{ Noncoronal word } \\
\hline Identity & tep-Teppich (match) & gra-Grabung (match) \\
Variation & kep-Teppich (no-mismatch) & dra-Grabung (mismatch) \\
Control & gra-Teppich & tep-Grabung \\
\hline
\end{tabular}

Note. The design applied in Experiment 2 is illustrated by using example trials. Three prime-target pairings were realized for coronal words and noncoronal words. Condition labels according to the ternary matching logic of the FUL model are given in parentheses.

coronal words were taken from noncoronal words, whereas unrelated pseudoword fragments for coronal words were taken from coronal words. The reverse combinations were made for noncoronal words. In sum, participants saw the same target word four times in randomized pairing; repetition was no less than three trials apart. This is not the normal procedure in a behavioral experiment, where participants encounter each stimulus only once and the experimental items are usually hidden within a large number of fillers. However, given the constraints of a methodologically sound ERP experiment, we could not adopt the customary restrictions for the behavioral experimental presentation of the stimuli in the present study.

Procedure. The electrophysiological measures were recorded following the same procedure as in Experiment 1. Participants sat in a sound attenuated booth. Visual stimuli were presented on a computer screen in front of the participants. Loudspeakers were placed to the left and to the right side of the screen. An experimental trial began with the presentation of a fixation cross in the center of the screen. Participants were instructed to fixate on this cross as long as it appeared. The prime was presented via loudspeaker $300 \mathrm{~ms}$ later, while the fixation cross remained on the screen. Immediately following the auditory prime, the fixation cross was replaced by a visual word or pseudoword presented in uppercase white letters on a black background. The task was to judge as quickly and as correctly as possible whether the target was a word. Half the participants made "yes" responses with the thumb of their left hand and "no" responses with the thumb of their right hand. For the remaining participants, response hands were reversed. Reaction times were measured from stimulus onset with a timeout criterion of $1,300 \mathrm{~ms}$. The next trial started after a fixed interstimulus interval of 1,000 ms. Participants were given breaks after completing 180 trials.

Data analysis. Error rates were calculated for words. Reaction times and ERPs were calculated only for correct responses to words. Eye blinks and movements were systematically recorded from each participant before the experimental task started and used for artifact correction with BESA. Mean amplitudes were derived from the ERP data by calculating the mean (relative to a $200 \mathrm{~ms}$ prestimulus baseline).

We used the SAS statistical analysis system for statistical analyses. Two three-level factors (see also Table 3) entered the ANOVAs for behavioral data: relatedness (identity condition vs. variation condition vs. control condition) and coronality (coronal target words vs. noncoronal target words). In line with previous research that showed fine-grained matching in the ERPs recorded in fragment priming (Friedrich, 2005; Friedrich, Kotz, Friederici,
\& Alter, 2004), P350 effects were calculated within a time window of 300 to $400 \mathrm{~ms}$ after word onset. A second time window ranging from 400 to $600 \mathrm{~ms}$ was used for analyzing the central negativity. Four ROIs served to analyze ERP effects: left anterior-temporal electrode places including AF3, F1, F5, FT7, FT9, FC1, FC3, FC5, C5, C3, M1; right anterior-temporal electrode places including AF4, F2, F6, FT8, FT10, FC1, FC3, FC5, C5, C3, M1; left centro-posterior electrode places including: CP5, CP3, P3, P1, P7, TP7, PO1, PO9, O1, O9, CP1; and right centro-posterior electrode places including: CP6, CP4, P4, P2, P8, TP8, PO2, PO10, O2, $\mathrm{O} 10, \mathrm{CP} 2$. The factors hemisphere (left vs. right ROIs) and region (anterior vs. posterior) were added to the ANOVA accordingly. Degrees of freedom for the three-level factor relatedness were adjusted by using the Greenhouse-Geisser epsilon $(\varepsilon)$. We report partial eta-squared $\left(\eta_{p}^{2}\right.$; see Experiment 1$)$.

To illustrate topographical differences in the brain activity, minimum norm estimations were calculated using BESA. These distributed source analyses were made on grand average difference waveforms for the coronal match condition, the noncoronal match condition, the no-mismatch condition, and the mismatch condition, which were all subtracted from their respective control conditions. No additional filter was applied before source analysis. Depth weighting and spatiotemporal weighting (subspace correlation after single source scan) were used to calculate source solutions. Noise was estimated using the baseline of the coronal match condition.

\section{Results}

Behavioral results. Mean reaction times and error rates are shown in Table 4. ANOVAs for reaction times revealed a main effect of relatedness, $F_{1}(2,15)=64.89, p<.001, \varepsilon=0.76, \eta_{p}^{2}=$ $.81 ; F_{2}(2,59)=49.00, p<.001, \varepsilon=0.79, \eta_{p}^{2}=.45$. Responses in the identity condition were $53 \mathrm{~ms}$ faster than responses in the control condition, $F_{1}(1,15)=144.70, p<.001, \eta_{p}^{2}=.90 ; F_{2}(1$, $59)=64.37, p<.001, \eta_{p}^{2}=.52$; and $48 \mathrm{~ms}$ faster than responses in the variation condition, $F_{1}(1,15)=55.28, p<.001, \eta_{p}^{2}=.78$; $F_{2}(1,59)=14.05, p<.001, \eta_{\mathrm{p}}{ }^{2}=0.70$. By contrast, responses in the variation condition did not differ significantly from responses in the control condition, $F_{1}(1,15)=1.63, n s ; F_{2}(1,59)=$ $0.25, n s$. There was no significant interaction between factors relatedness and coronality for the reaction times, $F_{1}(2,15)=1.64$, $n s ; F_{2}(2,59)=0.75, n s$.

ANOVAs for error rates revealed a main effect of relatedness, $F_{1}(2,15)=22.89, p<.001, \varepsilon=0.73, \eta_{p}^{2}=.60 ; F_{2}(2,59)=$

Table 4

Mean Reaction Times (RT) From Target Onset and Error Rates (ER) Including Standard Deviations (In Brackets) For All Conditions of Experiment 2

\begin{tabular}{|c|c|c|c|c|c|c|c|c|}
\hline \multirow[b]{3}{*}{ Condition } & \multicolumn{4}{|c|}{ Coronal word } & \multicolumn{4}{|c|}{ Noncoronal word } \\
\hline & \multicolumn{2}{|c|}{$\mathrm{RT}(\mathrm{ms})$} & \multicolumn{2}{|c|}{$\mathrm{ER}(\%)$} & \multicolumn{2}{|c|}{$\mathrm{RT}(\mathrm{ms})$} & \multicolumn{2}{|c|}{ ER $(\%)$} \\
\hline & $M$ & $S D$ & $M$ & $S D$ & $M$ & $S D$ & $M$ & $S D$ \\
\hline Identity & 597 & 85 & 6.1 & 3.5 & 587 & 87 & 7.9 & 5.5 \\
\hline Variation & 639 & 88 & 16.6 & 9.3 & 641 & 87 & 12.5 & 6.7 \\
\hline Control & 648 & 83 & 12.2 & 8.0 & 643 & 79 & 15.5 & 9.9 \\
\hline
\end{tabular}


$11.57, p<.001, \varepsilon=0.69, \eta_{p}^{2}=.16$. In addition, there was a significant interaction of relatedness and coronality in the byparticipant analysis, $F_{1}(2,15)=6.67, p<.01, \varepsilon=0.79, \eta_{p}^{2}=.30$, that was not confirmed in the by-item analysis, $F_{2}(2,59)=1.83$, $n s$. Participants made 6 percent more errors in the control condition than in the identity condition for both types of target words: coronal, $F 2(1,15)=24.74, p<.001, \eta_{p}^{2}=62 ; F_{2}(1,59)=14.16$, $p<.001, \eta_{p}^{2}=.19$; noncoronal, $(1,15)=17.97, p<.001, \eta_{p}^{2}=$ $.54 ; F_{2}(1,59)=7.31, p<.01, \eta_{p}^{2}=.11$. For coronal words by-participant analysis revealed significantly more errors in the variation condition (no-mismatch) compared to the control condition, $F_{1}(1,15)=8.95, p<.01, \eta_{p}^{2}=.37$, but this was not confirmed by the by-item analysis, $F_{2}(1,59)=1.73, n s$. For noncoronal target words, error rates in the variation condition (mismatch) and in the control condition did not differ, $F_{1}(1,15)=$ $1.93, n s ; F_{2}(1,59)=0.48, n s$. Taken together, we did not find behavioral facilitation for words preceded by pseudoword fragments that diverged only in initial POA.

ERPs. The grand mean waveforms for words over selected electrode sites are plotted in Figure 2. Over frontal electrode positions, a negative-going peak followed by a positive-going deflection was visible within the first $200 \mathrm{~ms}$ after onset of visual words. This pattern was reversed over posterior electrode positions. These early ERP deflections were followed by a broad

\section{A Non-coronal target words}
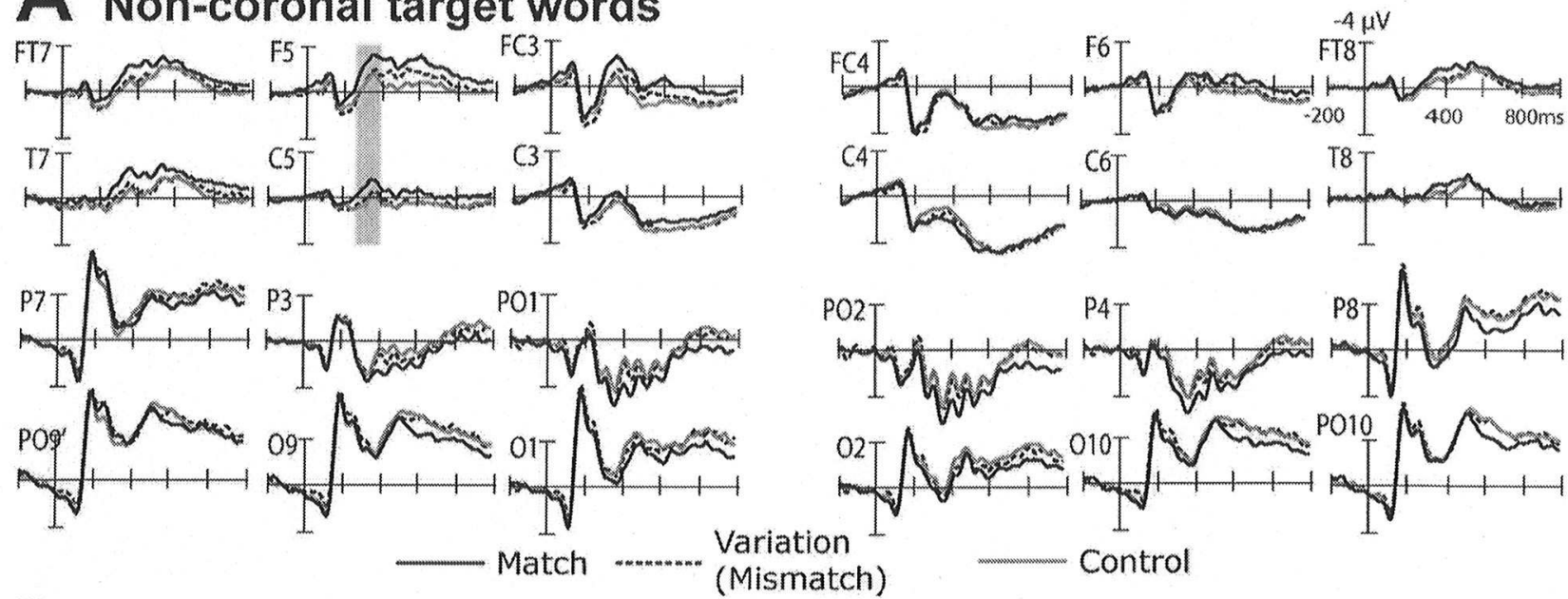

\section{B Coronal target words}

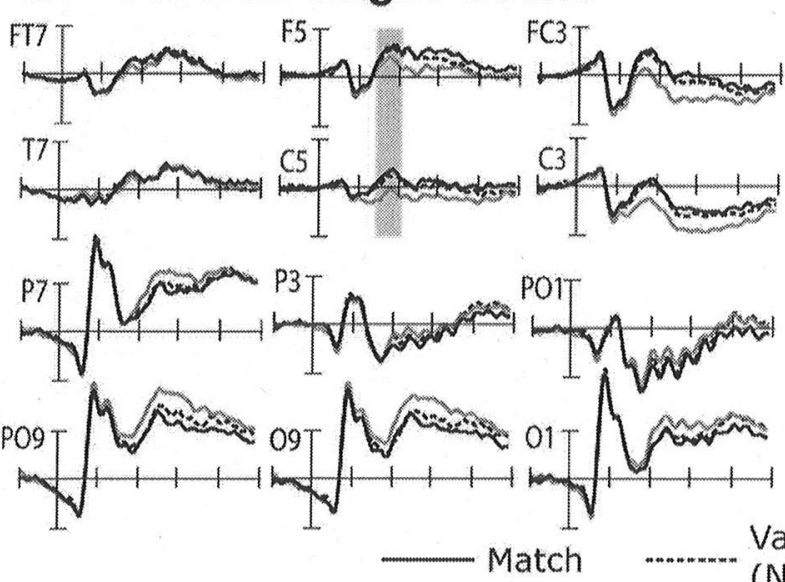

\section{Variation}

(Mismatch)

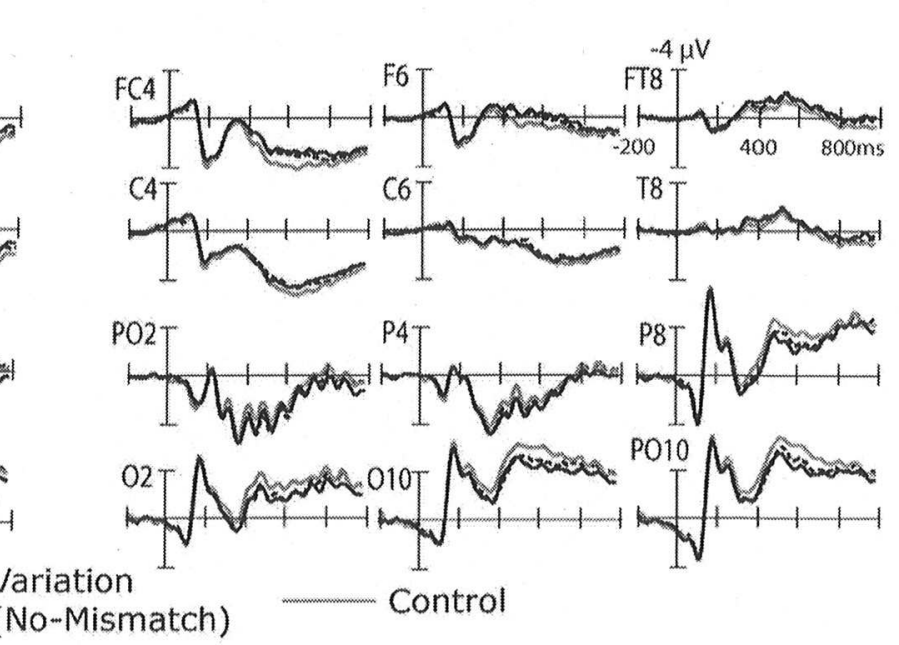

Figure 2. The grand average event-related brain potential (ERP) waveforms of Experiment 2 for selected electrode sites are plotted here. Black solid lines indicate the condition where words were preceded by fragments with the same place of articulation (match); black dashed lines where the same words were preceded by fragments with diverging place (variation). Note that according to the featurally underspecified lexicon model the variation condition represents a mismatch for noncoronal target words and a no-mismatch for coronal target words. Grey lines indicate the corresponding experimental conditions where words were preceded by unrelated fragments (control). ERPs start to be sensitive to place mismatches at $300 \mathrm{~ms}$ over left-frontal electrode positions. The P350 effect for the time window that is highlighted in grey is further illustrated in Figure 3. 
negativity over fronto-temporal electrode sites, which was sensitive to experimental manipulations. As seen in the difference waveforms of Figure 3, characteristic P350 effects were evoked. They revealed a left hemispheric source of the underlying neuronal activity. At posterior electrode sites, a positively peaking component at $400 \mathrm{~ms}$ was followed by an N400-like central negativity with enhanced amplitudes for the related compared to the control words.

ANOVA applied to the time window analyzed for the P350 effect (300-400 ms) revealed interactions of relatedness and region, $F(2,15)=16.82, p<.001, \varepsilon=0.99, \eta_{p}^{2}=.99$; of relatedness and hemisphere, $F(2,15)=34.51, p<.001, \varepsilon=0.74$, $\eta_{p}^{2}=.70$; and an interaction of these three factors, $F(2,15)=3.69$, $p=.04, \varepsilon=0.99, \eta_{p}^{2}=.19$. The interactions point to $\mathrm{P} 350$ effects with a frontal topography and a left-frontal maximum, which replicates P350 effects previously observed (Friedrich, 2005;
Friedrich, Kotz, Friederici, \& Alter, 2004): least positive-most negative amplitudes were elicited in the identity condition, medium amplitudes were evoked in the variation condition, and most positive-least negative amplitudes were obtained for the control condition (see Figure 2).

With respect to our assumption, it is most interesting that an interaction of factors relatedness, coronality, and region, $F(2$, $15)=4.12, p<.04, \varepsilon=0.85, \eta_{p}^{2}=.22$, suggested different P350 effects for both types of coronal and noncoronal target words. An interaction of factors relatedness and coronality, $F(2,15)=4.62$, $p=.02, \varepsilon=0.92, \eta_{p}^{2}=.23$, for the anterior region was further support for this suggestion. For coronal target words, post hoc comparisons revealed that amplitudes for the variation condition (no-mismatch) differed from amplitudes elicited in the control condition, $F(1,15)=4.84, p=.04, \eta_{p}^{2}=.24$. That is, nomismatch elicited a P350 effect. By contrast, for noncoronal tar-

\section{A Non-coronal target words Difference waves (P350 effect)}

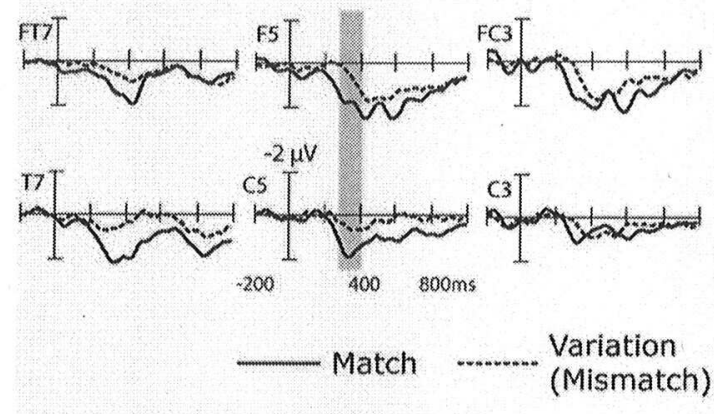

\section{B Coronal target words}

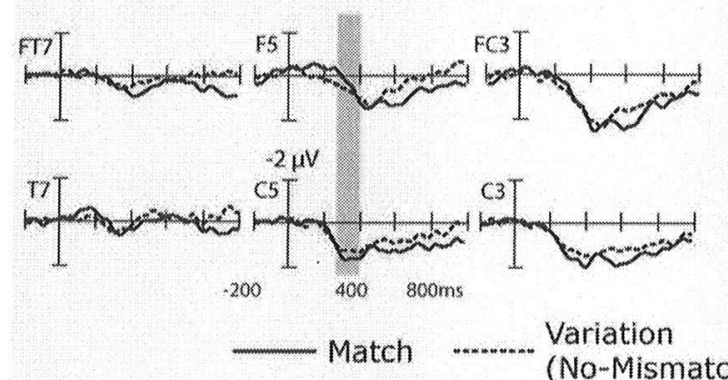

\section{Minimum norm solutions}

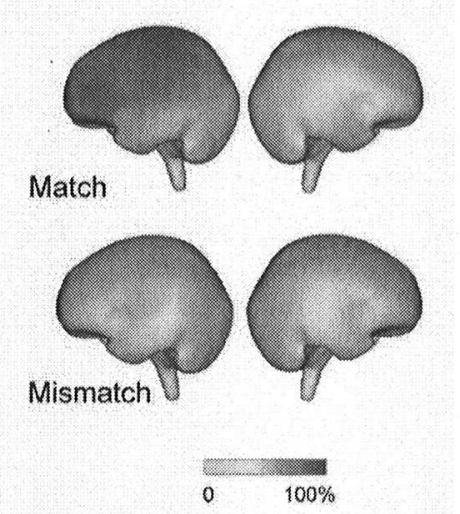

0

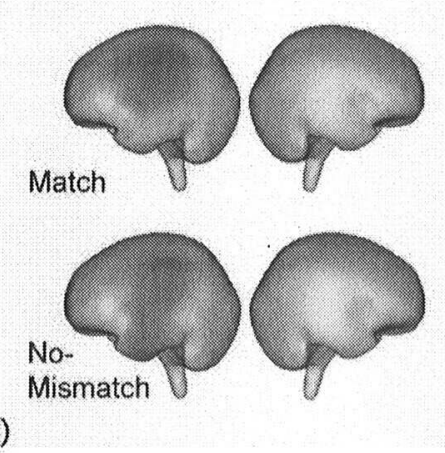

Figure 3. P350 effects for (A) noncoronal target words and (B) coronal target words. On the right, difference waves are shown (control words-match, solid lines; control words-mismatch, dashed lines) for selected left anterior electrode positions. The difference waveforms represent the P350 effect for matching words (solid lines). On the left, minimum norm solutions that estimate the neural sources underlying the P350 difference waves for the match condition are shown. Colors represent strength of dipole activation in percentages standardized across all conditions at $350 \mathrm{~ms}$. Note that reduced P350 difference waves were elicited for noncoronal target words preceded by coronal pseudoword onsets (mismatch; upper part: dashed lines and lower minimum norm solution). By contrast, P350 effects were not damaged for coronal target words preceded by noncoronal pseudoword onsets (no-mismatch; lower part: dashed lines and lower minimum norm solution). 
gets, post hoc comparisons revealed that amplitudes for the variation condition (mismatch) did not differ from amplitudes elicited in the control condition $F(1,15)=1.79, n s$. That is, mismatch did not evoke a P350 effect. This was confirmed by minimum norm estimates, which were calculated to better understand the localization of underlying neural processes of the P350 differences. Results suggested a left centro-temporal origin of neural sources engaged in the processing of matching words related to control words (see Figure 3). This replicated former minimum norm solutions of the P350 effect (Friedrich, 2005). Minimum norm solutions for no-mismatching words resembled that of matching words, whereas minimum norm solutions for mismatching words showed no P350 effect.

ANOVA of mean amplitudes in the time window of the central negativity $(400-600 \mathrm{~ms})$ revealed interactions of relatedness and region, $F(2,15)=32.22, p<.001, \varepsilon=0.95, \eta_{p}^{2}=.68$; relatedness and hemisphere, $F(2,15)=4.81, p=.03, \varepsilon=0.69, \eta_{p}^{2}=.69$; and an interaction of these three factors, $F(2,15)=11.70, p<.001$, $\varepsilon=0.95, \eta_{p}^{2}=.95$. As the central negativity reveals a posterior topography, we concentrated on this region. A separate ANOVA for posterior ROIs did not confirm hemispheric differences for the central negativity, $F(2,15)=1.75, n s$, but did confirm a main effect of relatedness, $F(2,15)=29.92, p<.001, \varepsilon=0.95, \eta_{p}^{2}=$ .66. Target words presented in the control condition elicited higher amplitudes of the central negativity than the same words presented in the match condition, $F(1,15)=48.44, p<.001, \eta_{p}^{2}=.76$. The variation condition differed from the control condition as well, $F(1,15)=20.49, p<.001, \eta_{p}^{2}=.42$. Note that there was no significant interaction with the factor coronality for ERP amplitudes elicited in the time window of the central negativity. Taken together, in contrast to the behavioral data, ERPs revealed priming for targets that varied from preceding prime fragments only in initial place of articulation.

\section{Discussion}

In Experiment 2 we tested by means of word fragment priming whether onsets of the pseudowords used for Experiment 1 differently activate the lexical entries of words they were derived from. On the basis of results of a previous study (Friedrich et al., 2006) and of Experiment 1, we hypothesized in accordance with predictions of the FUL model that onsets of coronal pseudoword variants (e.g., *Dren-) would not facilitate processing of noncoronal word targets (e.g., Grenze). By contrast, onsets of noncoronal pseudowords (e.g., $* B r a c h-$ ) should preactivate their respective words (e.g., Drachen). This was supported by neurophysiological measures: P350 effects reflected the predicted asymmetric activation pattern.

ERP results replicated P350 effects, which have been established in previous fragment priming research (Friedrich, 2005; Friedrich, Kotz, Friederici, \& Alter, 2004; Friedrich, Kotz, Friederici, \& Gunter, 2004). The present data support the notion that P350 effects are closely correlated with the activation status of neuronal word form representations in a modality-independent mental lexicon. Matching words diverged from unrelated words in the time window of the P350. In line with previous research, difference waves show a characteristic positive-going P350 effect.

Different P350 effects were observed for coronal and noncoronal words preceded by fragments that differ in initial POA. Coro- nal words preceded by noncoronal pseudoword fragments elicited a P350 effect compared to control words. This reveals that noncoronal pseudoword fragments indeed create a no-mismatch situation by activating coronal words. In contrast, noncoronal words preceded by coronal pseudowords did not elicit a P350 effect. This is in line with the assumed mismatch situation in which coronal pseudoword fragments do not efficiently activate noncoronal words. The observed asymmetric activation pattern parallels results from the behavioral priming literature (Gumnior et al., 2005; Lahiri \& Reetz, 2002; Wheeldon \& Waksler, 2004) and is in line with predictions of the FUL model.

In addition to the P350 effect, a central negativity was elicited in Experiment 2. Similar to previous studies (Friedrich, 2005; Friedrich, Kotz, Friederici, \& Alter, 2004; Friedrich, Kotz, Friederici, \& Gunter, 2004), the P350 effect and the central negativity can be distinguished as separate neurophysiological deflections in accordance with several relevant characteristics (see, e.g., Kutas \& Van Petten, 1994). Both ERP correlates differed with respect to latency, scalp topography, polarity of the elicited differences, and sensitivity to the experimental manipulation. Therefore, both ERP deflections most probably reflect at least two different processes, which both precede and modulate behavioral responses in fragment priming. The $\mathrm{P} 350$, on the one hand, appears to be related to the fine-grained mapping of the acoustic input onto lexical word form representations. The central negativity, on the other hand, might be related to phonological expectation and matching mechanisms.

Topography and polarity relate the central negativity to the phonological N400 (e.g., Praamstra \& Stegeman, 1993) and/or to the PMN (e.g., Connolly \& Phillips, 1994). In line with N400 priming effects, the central negativity is sensitive to the relationship between prime and target word. Enhanced amplitudes of the central negativity were found for unrelated as compared to related words. However, amplitudes of the central negativity were not reflecting asymmetric activation differences as predicted by the FUL model. This supports the notion that the central negativity reflects rough phonological matching rather than fine-grained lexical activation in fragment priming (Friedrich, 2005; Friedrich, Kotz, Friederici \& Alter, 2004). With respect to the FUL model, one might assume that phonological parsing mechanisms, which presumably also underlie the late N400 pseudoword effect as observed in Experiment 1, are the basis for the central negativity. It is crucial that, also in Experiment 2, both coronal and noncoronal pseudoword onsets mismatch the target in specified featural or phonemic information. Similar to Experiment 1, the late ERP data (central negativity) and the behavioral data were not sensitive to asymmetric preactivation due to the pseudoword fragments.

The present behavioral data are in line with former semantic priming results indicating that mismatch on an initial speech sound (e.g., *woning diverging in the initial sound from the Dutch word honing [honey]) does not facilitate responses to associates of the respective word (Marslen-Wilson \& Zwitserlood, 1989). This result led to the suggestion that mismatch in segmental information blocks lexical access. However, subsequent research has refined this conclusion, by showing, for example, that word initial variations like *gabinet or *mabinet facilitate responses to words like cabinet (Connine, Titone, Deelman, \& Blasko, 1997); or that *baprika primes the German word Paprika ([paprika]; Bölte \& Coenen, 2002). Also all former fragment priming studies obtained 
gradual behavioral facilitation (Cooper, Cutler, \& Wales, 2002; Cutler \& Van Donselaar, 2001; Frauenfelder, Scholten, \& Content, 2001; Friedrich, 2005; Friedrich, Kotz, Friederici, \& Alter, 2004; Soto-Faraco et al., 2001). However, the present study reveals that gradual behavioral facilitation is not an obligatory finding in fragment priming. Nevertheless, although word initial place variation blocks behavioral facilitation, ERPs indicate spurious neuronal activation of no-mismatch in the P350 effect and in the central negativity. In this way ERPs provide a more sensitive measure of spoken word processing than behavioral data allow. Future research using neurophysiological measures might further challenge the conclusion that "even a small amount of mismatching information (i.e., of even less than one whole phoneme) is enough to disrupt word recognition." (McQueen, 2007, p. 39)

\section{General Discussion}

The most striking result of the present experiments is that neurocognitive signatures in the subsecond range reflect the fine structure of spoken word recognition. In line with a previous ERP study on word medial variation (Friedrich et al., 2006), we found evidence that noncoronal pseudowords activate coronal words. Noncoronal pseudowords elicited only small initial N400 pseudoword responses (Experiment 1), and their onsets appeared to activate neuronal word form representations of coronal words (Experiment 2). That is, a string like $*$ Brachen can activate Drachen. However, initial place variation is only tolerated if the place feature of the lexical representation is not specified. Coronal pseudowords elicited a large initial N400 response (Experiment 1), and their onsets did not activate noncoronal words (Experiment 2). That is, a string like $*$ Drenze could not activate Grenze. Our results are in line with the hypothesis that noncoronal words have their place specified in the mental lexicon. The extracted place information from coronal pseudowords mismatches the noncoronal place information specified in the mental lexicon. This mismatch leads to markedly reduced activation of noncoronal words.

It is crucial to note that word initial segments usually do not undergo assimilation. The fact that we found asymmetric activation in the present experiments with word initial variation as well as in a previous experiment with word medial variation (Friedrich et al., 2006) supports the assumption of the FUL model that context-free underspecification of the coronal place of articulation is a general principle in the mental lexicon.

In the present experiments we observed neurophysiological effects of longer latency (the late pseudoword N400 effect in Experiment 1 and the central negativity in Experiment 2) and behavioral data that do not show the asymmetry as the earlier neurophysiological effects. We might account for these effects by FUL's assumption of phonological parsing mechanisms that follow initially asymmetric activation. All effects have in common that they reflect analysis at a fully specified surface featural level and that they reject candidates according to this analysis. In Experiment 1 , decision times were equal for coronal and noncoronal word variants. Similarly, the late pseudoword N400 was enhanced for both types of pseudowords. This replicates results of a previous study with word medial variation (Friedrich et al., 2006). In Experiment 2, reaction times exclusively reflected facilitated processing of words that completely match the fragments in the surface level, and the central negativity reflected a rough phonemic matching.

One might speculate that phonemic parsing mechanisms enable the listener to detect mispronunciations in an artificial situation like lexical decision or priming tasks. However, some top-down phonological matching might well be in charge during everyday speech comprehension. Those mechanisms might enable the listener to restore nonsystematic variation (e.g., speech errors) or degraded speech (e.g., in noisy environments). Furthermore, those mechanisms might take surrounding segments into account, leading to the context-dependent processing of assimilated segments that has been observed previously (e.g., Gaskell \& MarslenWilson, 1996, 1998). With respect to these parsing processes there is certainly more to be done in future research.

\section{References}

Attias, J., \& Pratt, H. (1992). Auditory event related potentials during lexical categorization in the oddball paradigm. Brain and Language, 43, 230-239.

Baayen, H., Piepenbrock, R., \& Van Rijn, H. (1993). The CELEX lexical database [CD-ROM]. Philadelphia: University of Pennsylvania, Linguistic Data Consortium.

Bentin, S. (1987). Event-related potentials, semantic processes, and expectancy factors in word recognition. Brain and Language, 31, 308327.

Bölte, J., \& Coenen, E. (2002). Is phonological information mapped onto semantic information in a one-to-one manner? Brain and Language, 81 , 384-397.

Chwilla, D. J., Brown, C. M., \& Hagoort, P. (1995). The N400 as a function of the level of processing. Psychophysiology, 32, 274-285.

Chwilla, D. J., Hagoort, C. M., \& Brown, C. M. (1998). The mechanism underlying backward priming in a lexical decision task: Spreading activation versus semantic matching. Quarterly Journal of Experimental Psychology: Human Experimental Psychology, 51A, 531-560.

Coenen, E., Zwitserlood, P., \& Bölte, J. (2001). Variation and assimilation in German: Consequences for lexical access and representation. Language and Cognitive Processes, 16, 535-564.

Connine, C. M., Titone, D., Deelman, T., \& Blasko, D. G. (1997). Similarity mapping in spoken word recognition: Evidence from phoneme monitoring. Journal of Memory and Language, 37, 463-480.

Connolly, J. F., \& Phillips, N. A. (1994). Event-related potential components reflect phonological and semantic processing of the sentence terminal word in spoken sentences. Journal of Cognitive Neuroscience, 6, 256-266

Cooper, N., Cutler, A., \& Wales, R. (2002). Constraints of lexical stress on lexical access in English: Evidence from native and nonnative listeners. Language and Speech, 45, 207-228.

Cutler, A., \& Van Donselaar, W. A. (2001). Voornaam is not (really) a homophone: Lexical prosody and lexical access in Dutch. Language and Speech, 44, 171-195.

Dumay, N., Benrais, A., Barriol, B., Colin, C., Radeau, M., \& Besson, M. (2001). Behavioral and electrophysiological study of phonological priming between bisyllabic spoken words. Journal of Cognitive Neuroscience, 13, 121-143.

Eulitz, C., \& Lahiri, A. (2004). Neurobiological evidence for abstract phonological representations in the mental lexicon during speech recognition. Journal of Cognitive Neuroscience, 16, 577-583.

Fitzpatrick, J., \& Wheeldon, L. (2000). Phonology and phonetics in psycholinguistic models of speech perception. In N. Burton-Roberts, P. Carr, \& G. Docherty (Eds.), Phonological knowledge (pp. 131-159). Oxford, England: Oxford University Press.

Frauenfelder, U. H., Scholten, M., \& Content, A. (2001). Bottom-up 
inhibition in lexical selection: Phonological mismatch effects in spoken word recognition. Language and Cognitive Processes, 16, 583-607.

Friedrich, C. K. (2005). Neurophysiological correlates of mismatch in lexical access. BMC Neuroscience, 6, 64

Friedrich, C. K., Eulitz, C., \& Lahiri, A. (2006). Not every pseudoword disrupts word recognition: An ERP study. Behavioral and Brain Functions, 2, 36.

Friedrich, C. K., Kotz, S. A., Friederici, A. D., \& Alter, K. (2004). Pitch modulates lexical identification in spoken word recognition: ERP and behavioral evidence. Cognitive Brain Research, 20, 300-308.

Friedrich, C. K., Kotz, S. A., Friederici, A. D., \& Gunter, T. C. (2004). ERPs reflect lexical identification in word fragment priming. Journal of Cognitive Neuroscience, 16, 541-552.

Gaskell, M. G., \& Marslen-Wilson, W. D. (1996). Phonological variation and inference in lexical access. Journal of Experimental Psychology: Human Perception and Performance, 22, 144-158.

Gaskell, M. G., \& Marslen-Wilson, W. D. (1998). Mechanisms of phonological inference in speech perception. Journal of Experimental Psychology: Human Perception and Performance, 24, 380-396

Gaskell, M. G., \& Marslen-Wilson, W. D. (2001). Lexical ambiguity resolution and spoken word recognition: Bridging the gap. Journal of Memory and Language, 45, 325-349.

Gow, D. W. (2001). Assimilation and anticipation in continuous spoken word recognition. Journal of Memory and Language, 45, 133-159.

Gow, D. W. (2002). Does English coronal place assimilation create lexical ambiguity? Journal of Experimental Psychology: Human Perception and Performance, 28, 163-179.

Gow, D. W. (2003). Feature parsing: Feature cue mapping in spoken word recognition. Perception and Psychophysics, 65, 575-590.

Gumnior, H., Zwitserlood, P., \& Bölte, J. (2005). Assimilation in existing and novel German compounds. Language and Cognitive Processes, 20 , 465-488.

Hagoort, P., \& Brown, C. M. (2000). ERP effects of listening to speech: Semantic ERP effects. Neuropsychologia, 38, 1518-1530.

Holcomb, P. J. (1993). Semantic priming and stimulus degradation: Implications for the role of the $\mathrm{N} 400$ in language processing. Psychophysiology, 30, 47-61.

Holcomb, P. J., Grainger, J., \& O'Rourke, T. (2002). An electrophysiological study of the effects of orthographic neighborhood size on printed word perception. Journal of Cognitive Neuroscience, 14, 838-850.

Kutas, M., \& Federmeier, K. (2000). Electrophysiology reveals semantic memory use in language comprehension. Trends in Cognitive Sciences, 4, 463-470.

Kutas, M., \& Hillyard, S. A. (1980). Reading senseless sentences: Brain potentials reflect semantic incongruity. Science, 207, 203-205.

Kutas, M., \& Van Petten, C. K. (1994). Psycholinguistics electrified: Event-related brain potential investigations. In M. A. Gernsbacher (Ed.), Handbook of psycholinguistics (pp. 161-163). San Diego, CA: Academic Press.

Lahiri, A., \& Marslen-Wilson, W. D. (1991). The mental representation of lexical form: A phonological approach to the recognition lexicon. Cognition, 38, 245-294

Lahiri, A., \& Marslen-Wilson, W. D. (1992). Lexical processing and phonological representation. In G. J. Docherty \& D. R. Ladd (Eds.), Papers in laboratory phonology: II (pp. 229-254). Cambridge, England: Cambridge University Press.

Lahiri, A., \& Reetz, H. (2002). Underspecified recognition. In C. Gussenhoven \& N. Werner (Eds.), Laboratory phonology VII (pp. 637-675). Berlin, Germany: Mouton.

Marslen-Wilson, W. (1990). Activation, competition and frequency in lexical access. In G. T. M. Altmann (Ed.), Cognitive models of speech processing: Psycholinguistic and computational perspectives (pp. 148172). Cambridge, MA: MIT Press.

Marslen-Wilson, W. D., \& Zwitserlood, P. (1989). Accessing spoken words: The importance of word onsets. Journal of Experimental Psychology: Human Perception and Performance, 15, 576-585.

McClelland, F. L., \& Elman, J. L. (1986). The TRACE model of speech perception. Cognitive Psychology, 18, 1-86.

McQueen, J. M. (2007). Eight questions about spoken word recognition. In M. G. Gaskell (Ed.), The Oxford handbook of psycholinguistics (pp. 37-53). Oxford, England: Oxford University Press.

Mitterer, H., \& Blomert, L. (2003). Coping with phonological assimilation in speech perception: Evidence for early compensation. Perception \& Psychophysics, 65, 956-969.

Mitterer, H., Csépe, V., Honbolygo, F., \& Blomert, L. (2006). The recognition of phonologically assimilated words does not depend on specific language experience. Cognitive Science, 30, 451-479.

Münte, T. F., Say, T., Clahsen, H., Schlitz, K., \& Kutas, M. (1999). Decomposition of morphologically complex words in English: Evidence from event-related brain potentials. Cognitive Brain Research, 7, 241253

Näätänen, R. (2001). The perception of speech sounds by the human brain as reflected by the mismatch negativity (MMN) and its magnetic equivalent (MMNm). Psychophysiology, 38, 1-21.

Neely, J. H., Keefe, D. E., \& Ross, K. L. (1989). Semantic priming in the lexical decision task: Roles of prospective prime-generated expectancies and retrospective semantic matching. Journal of Experimental Psychology: Learning, Memory, and Cognition, 15, 1003-1019.

Nobre, A. C., \& McCarthy, G. (1994). Language-related ERPs: Scalp distributions and modulation by word type and semantic priming. Journal of Cognitive Neuroscience, 6, 233-255.

Norris, D., McQueen, J. M., \& Cutler, A. (2002). Bias effects in facilitatory phonological priming. Memory and Cognition, 30, 399-411.

Obleser, J., Eulitz, C., \& Lahiri, A. (2004). Magnetic brain response mirrors extraction of phonological features from spoken vowels. Journal of Cognitive Neuroscience, 16, 31-39.

Obleser, J., Scott, S. K., \& Eulitz, C. (2006). Now you hear it, now you don't: Transient traces of consonants and their nonspeech analogues in the human brain. Cerebral Cortex, 16, 1069-1076.

O'Rourke, T. B., \& Holcomb, P. J. (2002). Electrophysiological evidence for the efficiency of spoken word processing. Biological Psychology, 60 121-150.

Picton, T. W., \& Hillyard, S. A. (1988). Endogenous event-related potentials. In T. W. Picton (Ed.), Handbook of electroencephalography and clinical neurophysiology: Vol. 3. Human event-related potentials (pp. 361-426). Amsterdam: Elsevier.

Praamstra, P., Meyer, A. S., \& Levelt, W. M. J. (1994). Neurophysiological manifestations of auditory phonological processing: Latency variation of a negative ERP component timelocked to phonological mismatch. Journal of Cognitive Neuroscience, 6, 204-219.

Praamstra, P., \& Stegeman, D. F. (1993). Phonological effects on the auditory N400 event-related brain potential. Cognitive Brain Research, 1, 73-86.

Radeau, M., Morais, J., \& Dewier, A. (1989). Phonological priming between monosyllabic spoken words. Memory and Cognition, 17, 525535.

Rodriguez-Fornells, A., Münte, T. F., \& Clahsen, H. (2002). Morphological priming in Spanish verb forms: An ERP priming study. Journal of Cognitive Neuroscience, 14, 443-454.

Rugg, M. D. (1987). Event-related potentials and the interaction between orthographic and phonological information in a rhyme-judgment task. Brain and Language, 32, 336-361

Soares, I., Collet, L., \& Duclaux, R. (1991). Electrophysiological correlates of auditory lexical decision: An attempt to test the "cohort model." International Journal of Neuroscience, 57, 111-122.

Soto-Faraco, S., Sebastian-Galles, N., \& Cutler, A. (2001). Segmental and suprasegmental mismatch in lexical access. Journal of Memory and Language, 45, 412-432. 
Spinelli, E., Segui, J., \& Radeau, M. (2001). Phonological priming in spoken word recognition with bisyllabic targets. Language and Cognitive Processes, 16, 367-392.

Supp, G. G., Schlögl, A., Gunter, T. C., Bernard, M., Pfurtscheller, G., \& Petsche, H. (2004). Lexical memory search during N400: Cortical couplings in auditory comprehension. NeuroReport, 15, 1209-1213.

van den Brink, D., Brown, C. M., \& Hagoort, P. (2001). Electrophysiological evidence for early contextual influences during spoken-word recognition: N200 versus N400 effects. Journal of Cognitive Neuroscience, 13, 967-985.
Weber, A. (2001). Help or hindrance: How violation of different assimilation rules affects spoken-language processing. Language and Speech, 44, 94-117.

Weber, A. (2003). Assimilation violation in spoken-language processing: A supplementary report. Language and Speech, 45, 37-46.

Wheeldon, L., \& Waksler, R. (2004). Phonological underspecification and mapping mechanisms in the speech recognition lexicon. Brain and Language, 90, 401-412.

Zwitserlood, P. (1996). Form priming. Language and Cognitive Processes, 11, 589-596.

\section{Appendix}

German Words and Pseudowords Used in Experiments 1 and 2

\begin{tabular}{|c|c|c|c|}
\hline Noncoronal word & Coronal pseudoword & Noncoronal word & Coronal pseudoword \\
\hline Balken [arbor] & Dalken & Dackel [dachsuhund] & Gackel \\
\hline Bande [gang] & Dande & Dampfer [steam ship] & Gampfer \\
\hline Besen [broom] & Desen & Delta [delta] & Belta \\
\hline Binde [bandage] & Dinde & Dichter [poet] & Bichter \\
\hline Börse [stock market] & Dörse & Dirne [courtesan] & Girne \\
\hline Borte [braid] & Dorte & Disko [disco] & Gisko \\
\hline Braue [brow] & Draue & Distel [thistle] & Gistel \\
\hline Bruder [brother] & Druder & Dogma [dogma] & Gogma \\
\hline Bürger [citizen] & Dürger & Dohle [jackdaw] & Gohle \\
\hline Bursche [bloke] & Dursche & Dosis [dose] & Gosis \\
\hline Garten [garden] & Darten & Drachen [dragon] & Brachen \\
\hline Geige [fiddle] & Deige & Droge [drug] & Groge \\
\hline Gitter [fence] & Ditter & Drossel [thrush] & Brossel \\
\hline Gondel [gondola] & Dondel & Dübel [rawlplug] & Gübel \\
\hline Grabung [excavation] & Drabung & Duldung [toleration] & Buldung \\
\hline Grafik [graphic] & Drafik & Düne [dune] & Güne \\
\hline Gräuel [horror] & Dräuel & Dünger [dung] & Bünger \\
\hline Grenze [border] & Drenze & Dürre [drought] & Bürre \\
\hline Grotte [grotto] & Drotte & Dusche [shower] & Gusche \\
\hline Grube [cavity] & Drube & Dussel [goof] & Gussel \\
\hline Grütze [porridge[ & Drütze & Narbe [scar] & Marbe \\
\hline Gülle [liquid manure] & Dülle & Nebel [mist] & Mebel \\
\hline Gurke [cucumber] & Durke & Nektar [nectar] & Mektar \\
\hline Kaftan [caftan] & Taftan & Nichte [niece] & Michte \\
\hline Käse [cheese] & Täse & Nickel [nickel] & Mickel \\
\hline Kerker [dungeon] & Terker & Niesel [drizzle] & Miesel \\
\hline Kobold [goblin] & Tobold & Nonne [nun] & Monne \\
\hline Köder [bait] & Töder & Nuckel [teat of baby's bottle] & Muckel \\
\hline Kolben [piston] & Tolben & Nudel [pasta] & Mudel \\
\hline Konto [bank account] & Tonto & Nugat [nougat] & Mugat \\
\hline Kippel [belt] & Toppel & Tagung [conference] & Kagung \\
\hline Krabbe [crab] & Trabbe & Taube [dove] & Kaube \\
\hline Kühle [chill] & Tühle & Täufer [baptist] & Päufer \\
\hline Kummer [grief] & Tummer & Technik [technique] & Kechnik \\
\hline Kumpel [mate, buddy] & Tumpel & Tempo [speed] & Pempo \\
\hline Künstler [artist] & Tünstler & Teppich [carpet] & Keppich \\
\hline Kurve [curve] & Turve & Tiefe [depth] & Piefe \\
\hline Magma [magma] & Nagma & Tiger [tiger] & Piger \\
\hline Mantel [coat] & nantel & Tilgung [deletion] & Kilgung \\
\hline Maske [mask] & Naske & Tinte [ink] & Kinte \\
\hline Masten [mast] & Nasten & Toaster [toaster] & Koaster \\
\hline Meister [master [craftsman]] & Neister & Tochter [daughter] & Pochter \\
\hline Monster [monster] & Nonster & Tonne [ton] & Konne \\
\hline Möwe [sea-gull] & Nöwe & Trage [stretcher] & Prage \\
\hline Muster [pattern] & Nuster & Traktor [tractor] & Kraktor \\
\hline Pächter [tenant] & Tächter & Trampel [clumsy oaf] & Prampel \\
\hline
\end{tabular}


Appendix (continued)

\begin{tabular}{ll|ll}
\hline \multicolumn{1}{c|}{ Noncoronal word } & Coronal pseudoword & \multicolumn{1}{c}{ Noncoronal word } & Coronal pseudoword \\
\hline Pappel [poplar] & Tappel & Träne [tear drop] & Präne \\
Pendel [pendulum] & Tendel & Tränke [drinking trough] & Pränke \\
Perle [pearl] & Terle & Traube [grape] & Kraube \\
Pille [pill] & Tille & Trauer [mourning] & Prauer \\
Pinsel [brush] & Tinsel & Treiber [driver] & Preiber \\
Pocke [pock mark] & Tocke & Treppe [stairs] & Kreppe \\
Poker [poker] & Toker & Trichter [funnel] & Prichter \\
Pranger [pillory] & Tranger & Tundral [misery] & Krübsal \\
Prater [Vienna fairground] & Trater & Tunnel [tunnel] & Pundra \\
priester [priest] & Triester & Tupfer [swab] & Punnel \\
Prisma [prism] & Trisma & Türke [Turk] & Pupfer \\
Probe [test] & Trobe & Turner [gymnast] & Pürke \\
Puppe [puppet] & Tuppe & & Purner \\
Puste [breathe] & Tuste & & \\
\hline
\end{tabular}

